declared, Clementina López-Medina: None declared, Maxime Dougados: None declared, Victoria Navarro-Compán: None declared.

DOI: 10.1136/annrheumdis-2021-eular.1410

\section{POS0970 ASSESSMENT OF THE ASSOCIATION BETWEEN ESTIMATED CARDIOVASCULAR RISK AND MASEI INDEX IN PATIENTS WITH AXIAL SPONDYLOARTHRITIS}

I. C. Aranda-Valera ${ }^{1,2,3}$, I. Gómez García ${ }^{1,2,3}$, M. L. Ladehesa Pineda ${ }^{1,2,3}$, M. C. Ábalos-Aguilera ${ }^{1,2,3}$, C. López-Medina ${ }^{1,2,3}$, E. Collantes Estevez ${ }^{1,2,3}$. $^{1}$ Reina Sofía Hospital, Rheumatology Service, Córdoba, Spain; ${ }^{2} I M I B I C$, Rheumatology Service, Córdoba, Spain; ${ }^{3}$ University of Córdoba, Rheumatology Service, Córdoba, Spain

Background: It has been shown that the cardiovascular risk (CV) in spondyloarthritis $(\mathrm{SpA})$ patients is higher than that of the general population. Furthermore, an association has recently been described between structural damage at the axial level and an increase in estimated CV risk ${ }^{1}$

Objectives: To evaluate the association between the estimated cardiovascular risk (CV) and the presence of subclinical atherosclerosis with the MASEI index (Madrid Sonographic Enthesis Index) in patients with axial spondyloarthritis $(\mathrm{Ax}-\mathrm{SpA})$ as an expression of peripheral enthesitis.

Methods: Cross-sectional study performed in 103 patients with ax-SpA from the Córdoba AxSpA Task force, Registry and Outcomes (CASTRO), in which patients undergoing treatment with biological therapy and with a previous history of CV event were excluded. Clinical data, disease activity data and factors related to CV risk were collected, as well as the presence of persistently elevated CRP levels in the five years prior to the study visit. The SCORE index was calculated, as well as the thickness of the carotid intima media (CIMT) and the MASEI index, both measured by ultrasound. The association between MASEI-SCORE and MASEI-atheroma plaques was evaluated using generalized linear models (GLM), adjusted for time of evolution of the disease, disease activity and smoking.

Results: Of the patients included, 35 were men (34.0\%), with a mean age of $45.2( \pm 12.1)$ years and time of evolution of the disease of $18.5( \pm 13.0)$ years. The mean MASEI score was $13.6( \pm 9.1)$, and the mean SCORE score was $8.1( \pm 8.9)$. The GLM regressions showed that the MASEI was independently associated with the SCORE (coefficient $\beta 0.22 ; 95 \% \mathrm{Cl} 0.02-0.43$ ) adjusted for the duration of the disease, smoking, and the presence of persistent CRP (Table 1A). The MASEI index was also significantly associated with the CIMT, although these differences disappeared when the model was adjusted for other factors (Table 1B).

Table 1. A. Association between MASEI and SCORE adjusting for disease duration, smoking status and CRP.

\begin{tabular}{|c|c|c|c|c|c|c|c|c|}
\hline & \multicolumn{2}{|c|}{ Crude model } & \multicolumn{2}{|c|}{$\begin{array}{l}\text { Adjusted for disease } \\
\text { duration }\end{array}$} & \multicolumn{2}{|c|}{$\begin{array}{l}\text { Adjusted for disease } \\
\text { duration and } \\
\text { smoking }\end{array}$} & \multicolumn{2}{|c|}{$\begin{array}{l}\text { Adjusted for disease } \\
\text { duration, smoking } \\
\text { and CRP }\end{array}$} \\
\hline & $\begin{array}{c}\beta \text { coef- } \\
\text { ficient } \\
(95 \% \mathrm{Cl})\end{array}$ & p-value & $\begin{array}{c}\beta \text { coef- } \\
\text { ficient } \\
(95 \% \mathrm{Cl})\end{array}$ & p-value & $\begin{array}{c}\beta \text { coef- } \\
\text { ficient } \\
(95 \% \mathrm{Cl})\end{array}$ & p-value & $\begin{array}{c}\beta \text { coef- } \\
\text { ficient } \\
(95 \% \mathrm{Cl})\end{array}$ & p-value \\
\hline MASEI & $\begin{array}{c}0.37 \\
(0.20-0.55)\end{array}$ & $<0.001$ & $\begin{array}{c}0.25 \\
(0.08-0.42)\end{array}$ & 0.006 & $\begin{array}{c}0.25 \\
(0.09-0.42)\end{array}$ & 0.004 & $\begin{array}{c}0.22 \\
(0.02-0.43)\end{array}$ & 0.039 \\
\hline
\end{tabular}

Conclusion: In patients with ax-SpA, peripheral enthetic damage measured by the MASEI index is associated with an increase in estimated CV risk independently of the time of evolution, smoking and levels of CRP. REFERENCES:

[1] Ladehesa-Pineda ML, Arias-de la Rosa I, López-Medina C, et al. Assesment of the relationship between estimated cardiovascular risk and structural damage in patients with axial spondyloarthritis. Ther Adv Musculoskelet Dis 2020;12:1-15

Table 1. B. Association between MASEI and intima media thickness (IMT) adjusting for disease duration, smoking status and CRP.

\begin{tabular}{|c|c|c|c|c|c|c|c|c|}
\hline & \multicolumn{2}{|c|}{ Crude model } & \multicolumn{2}{|c|}{$\begin{array}{l}\text { Adjusted for disease } \\
\text { duration }\end{array}$} & \multicolumn{2}{|c|}{$\begin{array}{l}\text { Adjusted for } \\
\text { disease duration } \\
\text { and smoking }\end{array}$} & \multicolumn{2}{|c|}{$\begin{array}{l}\text { Adjusted for disease } \\
\text { duration, smoking } \\
\text { and CRP }\end{array}$} \\
\hline & $\begin{array}{l}\beta \text { coef- } \\
\text { ficient } \\
(95 \% \mathrm{Cl})\end{array}$ & p-value & $\begin{array}{c}\beta \text { coefficient } \\
(95 \% \mathrm{Cl})\end{array}$ & $p$-value & $\begin{array}{c}\beta \text { coef- } \\
\text { ficient } \\
(95 \% \mathrm{Cl})\end{array}$ & p-value & $\begin{array}{c}\beta \text { coefficient } \\
(95 \% \mathrm{Cl})\end{array}$ & p-value \\
\hline MASEI & $\begin{array}{c}0.01 \\
(0.00-0.01)\end{array}$ & 0.041 & $\begin{array}{c}0.003 \\
(-0.01-0.004)\end{array}$ & 0.178 & $\begin{array}{c}0.002 \\
(-0.001- \\
0.004)\end{array}$ & 0.149 & $\begin{array}{c}0.002 \\
(-0.001- \\
0.005)\end{array}$ & 0.226 \\
\hline
\end{tabular}

Disclosure of Interests: None declared.

DOI: 10.1136/annrheumdis-2021-eular. 1525

\section{POS0971 \\ HOW DO CLINICAL AND SOCIOECONOMIC FACTORS IMPACT ON WORK DISABILITY IN EARLY AXIAL SPONDYLOARTHRITIS? FIVE-YEAR DATA FROM THE DESIR COHORT}

E. Nikiphorou ${ }^{1,2}$, A. Boonen ${ }^{3,4}$, B. Fautrel ${ }^{5}$, P. Richette ${ }^{6}$, R. B. M. Landewé ${ }^{7,8}$, D. Van der Heijde ${ }^{9}$, S. Ramiro ${ }^{7,9} .{ }^{1}$ King's College London, Centre for Rheumatic Diseases, London, United Kingdom; ${ }^{2}$ King's College Hospital NHS Trust, Rheumatology, London, United Kingdom; ${ }^{3}$ Maastricht University Medical Center and Care and Public Health Research Institute (CAPHRI), Rheumatology, Maastricht, Netherlands; ${ }^{4}$ Academic Hospital Maastricht, Internal Medicine, Division of Rheumatology, Maastricht, Netherlands;

${ }^{5}$ Sorbonne University - Assistance Publique Hopitaux de Paris, Pitie Salpetriere Hospital, Pierre Louis Institute for Epidemiology and Public Health, INSERM UMRS 1136, PEPITES Teams, Rheumatology, Paris, France;

${ }^{6}$ Université de Paris, Hopital Lariboisière, Rheumatology, Paris, France;

${ }^{7}$ Zuyderland MC, Rheumatology, Heerlen, Netherlands; ${ }^{8}$ Amsterdam University Medical Center, Rheumatology, Amsterdam, Netherlands; ${ }^{9}$ Leiden University Medical Center (LUMC), Rheumatology, Leiden, Netherlands

Background: There remains substantial unmet need to study work disability (WD) in early axSpA. Previous studies suggest that treatment interventions alone do not improve work outcomes and that socioeconomic (SE) as well as clinical factors may play an important role.

Objectives: To investigate the occurrence of WD and the impact of clinical and SE factors on WD in early axial spondyloarthritis (axSpA).

Methods: Patients with a clinical diagnosis of axSpA from the DESIR cohort up to 5 years of follow-up (6-month visits in the first 2 years, followed by annual visits) were studied. Time to WD and potential baseline and time-varying predictors were explored, with a focus on SE variables: age, gender, smoking status since last visit, ethnicity (Caucasian vs other), job type based on 'collar' (blue vs white), educational status (low vs high -university), marital status (married vs not) and parenta status (number of children); and clinical factors: disease activity (ASDAS/BASDAI), function (BASFI), mobility (BASMI), at each time point. The incidence of WD was calculated as the number of WD events over the total number of person-days under observation. Univariable analyses, followed by collinearity and interaction tests, guided subsequent multivariable Cox survival analyses.

Results: A total of 704 axSpA patients with work-related data, mean (SD) age 33.8 (8.6), were studied. The estimated incidence of WD amongst those at risk and across the five years of DESIR, was $0.05(95 \% \mathrm{CI} 0.03,0.06)$ per 1000 days (total person-days of observation of 999,999 ). Mean (SD) time to WD was 976 days (SD 476), (min 163, max 2021 days). In people who developed WD, $25 \%$ did so at 595 days; $50 \%$ and $75 \%$ at 1050 and 1433 days, respectively. Significant differences in age, level of education, marital and parental status as well as disease activity, function and mobility, all at baseline, were seen between those developing WD vs those who never did. In multivariable models (Table 1), older age, higher ASDAS and BASFI all strongly predicted more WD $(p<0.005)$. In separate models adjusted for age, gender and education, BASFI and BASMI both predicted WD. SE factors, including education attained, were not associated with a risk for WD. There were no relevant interactions between clinical variables and SE factors.

Table 1. Univariable and multivariable model analyses with WD as outcome.

\begin{tabular}{|c|c|c|c|}
\hline \multirow[t]{2}{*}{ Type of analysis } & Univariable & $\begin{array}{c}\text { Multivariable } \\
\text { model } \\
\text { Focus on ASDAS }\end{array}$ & $\begin{array}{c}\text { Multivariable model } \\
\text { Focus on BASFI/ } \\
\text { BASMI }\end{array}$ \\
\hline & $\mathrm{HR}(95 \% \mathrm{Cl})$ & $\begin{array}{c}\mathrm{HR}(95 \% \mathrm{Cl}) \\
\quad(\mathrm{N}=653)\end{array}$ & $\begin{array}{c}\mathrm{HR}(95 \% \mathrm{Cl}) \\
(\mathrm{N}=639)\end{array}$ \\
\hline \multicolumn{4}{|l|}{ Explanatory variables } \\
\hline Age & $1.07(1.04,1.11)$ & $1.06(1.02,1.10)$ & $1.03(0.99,1.08)$ \\
\hline Male gender & $0.68(0.37,1.23)$ & $1.10(0.58,2.08)$ & $1.00(0.50,2.02)$ \\
\hline High education & $0.25(0.14,0.48)$ & $0.57(0.29,1.11)$ & $0.42(0.19,0.90)$ \\
\hline Parental status & $1.36(1.09,1.70)$ & NS & NS \\
\hline ASDAS (CRP) & $2.40(1.77,3.26)$ & $1.79(1.27,2.54)$ & Not tested \\
\hline BASFI, $0-10$ & $1.54(1.36,1.75)$ & $1.42(1.22,1.65)$ & $1.53(1.29,1.81)$ \\
\hline BASMI, 0-10 & $2.13(1.65,2.75)$ & NS & $1.49(1.10,2.00)$ \\
\hline Symptom duration & $0.79(0.56,1.12)$ & NS & NS \\
\hline HLA B27 positive & $0.64(0.36,1.13)$ & NS & NS \\
\hline Hip involvement (baseline) vs not & $1.98(1.02,3.82)$ & NS & NS \\
\hline Comorbidity count & $2.33(1.68,3.21)$ & NS & NS \\
\hline NSAID use last $6 \mathrm{~m}$ (vs no use) & $1.01(1.00,1.02)$ & NS & NS \\
\hline Oral Corticosteroid use (vs no) & $2.72(1.27,5.83)$ & NS & NS \\
\hline csDMARD use last $6 m$ (vs no) & $2.20(0.90,5.41)$ & NS & NS \\
\hline TNFi use & $2.15(1.19,3.87)$ & NS & NS \\
\hline
\end{tabular}

NS=Not significant

Conclusion: In this early axSpA cohort, WD was an infrequent event. Nevertheless, clinical factors are amongst the strongest predictors of WD, over SE factors, 
with worse disease activity, function and mobility all independently implicated with more WD in early axSpA. Disease severity remains a strong predictor of adverse work outcome, despite substantial advances in therapeutic strategies in axSpA.

Disclosure of Interests: None declared

DOI: 10.1136/annrheumdis-2021-eular.1596

\section{POS0972 CLUSTER ANALYSIS OF ANKYLOSING SPONDYLITIS PATIENTS REVEALS DIFFERENTIAL DRUG SURVIVAL OF ANTI-TNF AGENTS ACCORDING TO DISTINCT CLINICAL PHENOTYPE}

S. Lee ${ }^{1}$, S. Y. Kang ${ }^{1}$, Y. H. Eun ${ }^{1}$, H. Kim¹, H. S. Cha' ${ }^{1}$, E. M. Koh ${ }^{1}$, J. Lee ${ }^{1}$. ${ }^{1}$ Samsung Medical Center, Sungkyunkwan University School of Medicine, Department of Medicine, Seoul, Korea, Republic of (South Korea)

Background: Previous studies using cluster analysis technique in ankylosing spondylitis (AS) patients have consistently identified distinct groups of patients in terms of their clinical characteristics: those with pure axial symptoms and those with a high frequency of peripheral manifestations [1,2]. Due to the cross-sectional nature of these studies, however, prognostic information such as drug survival of anti-TNF agents in these group were not provided.

Objectives: Using the data retrieved from Korean College of Rheumatology Biologics (KOBIO) registry, which includes longitudinal data of AS patients using anti-TNF agents, this study aims to perform cluster analysis to differentiate AS patients in terms of clinical phenotypes and to examine the differential drug survival of anti-TNF agents in these groups.

Methods: Clinical characteristics and demographic data of AS patients in KOBIO registry were analyzed using hierarchical clustering analysis. After clustering, drug survivals of anti-TNF agents were compared between these groups.

Results: 1,046 patients were included in the study with no missing data. The hierarchical cluster analysis classified patients in two groups; one with predominant isolated axial manifestations (axial group, $n=823$ ) and the other with more frequent extra-axial symptoms (extra-axial group, $n=223$ ). Almost all extra-axial symptoms (peripheral arthritis, enthesitis, uveitis, dactylitis, and psoriasis) were more frequently observed in extra-axial group than axial group. In addition, patients with shorter disease duration, late disease onset, and high disease activity were classified in extra-axial group (Table 1). Interestingly, the extra-axial group had lower drug survival probability than the axial group $(\mathrm{p}=0.008$, Figure 1 ).

Conclusion: Cluster analysis of AS patients using anti-TNF agents classified two distinct groups of patients in terms of their clinical phenotypes and revealed that the patients with prominent extra-axial manifestations had lower drug survival with anti-TNF agents.

REFERENCES:

[1] Costantino F, et al. Two Phenotypes Are Identified by Cluster Analysis in Early Inflammatory Back Pain Suggestive of Spondyloarthritis: Results From the DESIR Cohort. Arthritis Rheumatol. 2016 Jul;68(7):1660-8.

[2] Porcher R, et al. Two major spondylarthropathy phenotypes are distinguished by pattern analysis in multiplex families. Arthritis Rheum. $2005 \mathrm{Apr}$ 15;53(2):263-71.

Table 1. Clinical characteristics of divided groups

\begin{tabular}{|c|c|c|c|}
\hline Group & 1 (axial group) & 2 (extra-axial group) & $\mathrm{p}$ \\
\hline Number of patients & 823 & 223 & \\
\hline Age at start of TNFi (yr) & $38.21(12.78)$ & $38.58(14.17)$ & 0.713 \\
\hline Disease duration (yr) & $3.95(5.26)$ & $2.29(4.32)$ & $<0.001$ \\
\hline Age at diagnosis & $34.27(13.05)$ & $36.29(14.11)$ & 0.044 \\
\hline Sex (male) (\%) & $645(78.4)$ & $152(68.2)$ & 0.002 \\
\hline HLA-B27 positivity (\%) & $736(89.4)$ & 197 (88.3) & 0.732 \\
\hline Inflammatory back pain (\%) & $699(84.9)$ & $191(85.7)$ & 0.872 \\
\hline Peripheral arthritis (\%) & $201(24.4)$ & $191(85.7)$ & $<0.001$ \\
\hline Enthesitis (\%) & $65(7.9)$ & $154(69.1)$ & $<0.001$ \\
\hline Uveitis (\%) & $163(19.8)$ & $59(26.5)$ & 0.039 \\
\hline Dactylitis (\%) & $12(1.5)$ & $13(5.8)$ & $<0.001$ \\
\hline Psoriasis (\%) & $15(1.8)$ & $12(5.4)$ & 0.006 \\
\hline Good response to NSAIDs (\%) & $205(24.9)$ & $155(69.5)$ & $<0.001$ \\
\hline Family history (\%) & $88(10.7)$ & $27(12.1)$ & 0.632 \\
\hline Smoking (\%) & $408(49.6)$ & $102(45.7)$ & 0.347 \\
\hline CRP (mg/dl) & $2.10(2.74)$ & $2.89(3.57)$ & $<0.001$ \\
\hline $\mathrm{ESR}(\mathrm{mm} / \mathrm{hr})$ & $35.52(28.73)$ & 46.33 (32.94) & $<0.001$ \\
\hline BASDAI & $5.93(1.92)$ & $6.41(1.80)$ & 0.001 \\
\hline BASF & $3.42(2.56)$ & $3.64(2.58)$ & 0.255 \\
\hline Drug change after one year (\%) & $160(19.4)$ & $61(27.4)$ & 0.013 \\
\hline
\end{tabular}

Figure 1. Kaplan-Meier survival analysis of TNFi use in two groups.

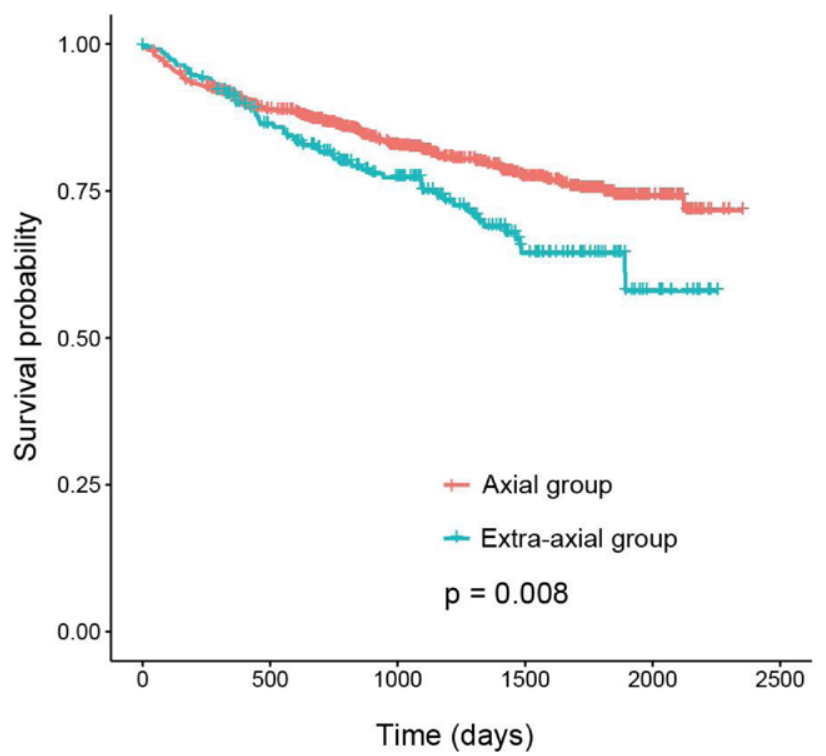

Disclosure of Interests: None declared.

DOI: 10.1136/annrheumdis-2021-eular.1772

\section{POS0973 \\ CONTEXTUAL FACTORS SHOULD COMPLETE THE ASSESSMENT OF FUNCTIONING IN PATIENTS WITH AXIAL SPONDYLOARTHRITIS (AXSPA)}

U. Kiltz ${ }^{1}$, E. Ahomaa ${ }^{2}$, B. Buehring ${ }^{1}$, X. Baraliakos ${ }^{1}$, D. Kiefer ${ }^{1}$, J. D. Leicht ${ }^{1}$, J. Braun ${ }^{1}{ }^{1}$ Rheumazentrum Ruhrgebiet at Ruhr-University Bochum,

Rheumatology, Herne, Germany; ${ }^{2}$ St. Franziskus-Hospital, Department of Orthopedic Surgery, Cologne, Germany

Background: Functioning of patients (pts.) with axial spondyloarthritis (axSpA) is influenced by a variety of factors. In contrast to clinical factors, the influence of contextual factors on functioning has not been well studied. According to the According to the International Classification of Functioning, Disability and Health (ICF), functioning is a complex interaction between health status and contextual factors such as social support, relationships and attitudes.

Objectives: The aim of this study is to understand limitations in participation and to investigate barriers and facilitators of contextual factors in pts. with axSpA. Methods: Consecutive axSpA pts. underwent a standardized assessment with collection of patient and disease characteristics, patient-reported outcomes (ASDAS, BASFI, BASMI, PHQ-9, ICF Measure of Participation and ACTivities questionnaire (IMPACT-S (0-100\%)), ASAS Health Index (ASAS HI and environment factor item set (EFIS) (1). The EFIS contains 9 dichotomous questions addressing ICF categories of products and technologies (e1), support and relationship (e3), attitudes (e4) and health services (e5). Validated cut-offs of ASAS $\mathrm{HI}$ were used to categorize global functioning.

Results: A total of 200 axSpA pts. were included: $69 \%$ males, $44.3 \pm 12.5$ years, symptom duration $17.9 \pm 12.6$ years, ASDAS $2.5 \pm 1.1, \mathrm{BASFI} 4.0 \pm 2.7$, BASMI $3.5 \pm 1.8$ ASAS HI 7.0 \pm 4 .1. Pts. reported limitations in the IMPACT-S activity and participation domain $(82.3 \%$ (15.2) and $83.5 \%$ (16.8), respectively. The majority of pts. reported as barrier that treatment of axSpA requires time (e4, 58.5\%). A minority of pts. but quite a few reported as barrier the need for support by family members (e3, $43.5 \%$ ), the need to modify home and work environment $(\mathrm{e} 1,39.5 \%)$ and that they cannot rely on family members for help (e3, 22\%). Some pts. $(<20 \%)$ reported that they have problems to be understood by health care professionals when experiencing a flare (e5, 18.5\%), that pts. at home are not adequately taken care of (e4, 18.5\%), disliking friends' behavior toward them $(\mathrm{e} 4,13.5 \%)$, and that friends are too demanding (e4, $13 \%)$. The majority of pts. (e4, $75.9 \%$ ) identified attitudes of friends as the only and major facilitator. All pts. reporting at least one barrier had significantly worse global functioning (ASAS HI, IMPACT-S), and depression (PHQ-9) compared to patients who reported no barriers in the respective ICF categories $(p<0.01)$. Similarly, pts. with poor functioning are more likely to report barriers in contextual factors compared to pts. with good functioning (Table 1). Pts. having to ask for more support from their families expressed the feeling that they cannot rely on that. 